\title{
Cyclophosphamide in Ovarian Cancer Subtypes: Time for a Comeback
}

Sir,

Paclitaxel replaced cyclophosphamide (CTX) as the standard partner to a platin in advanced ovarian cancer, based on controversial trials. However, with the present knowledge of molecular heterogeneity of ovarian cancer, and the known sensitivity of BRCA mutated/homologous recombination (HR) deficient subtypes to alkylating agents, it is proposed that CTX should be considered for reintroduction in this subgroup.

Standard first-line treatment of ovarian cancer is a combination of paclitaxel with either carboplatin or cisplatin, introduced in the 1990s after two trials showed the superiority of this regiment over the previous standard of CTX with cisplatin. The Gynecology Oncology Group trial (GOG-111) showed that the paclitaxel arm had improved progression-free survival and overall survival by 5 and 14 months, respectively. ${ }^{[1]}$ The European Canadian Intergroup trial (OV10) showed a similar improvement of 4 and 10 months. ${ }^{[2]}$ However, the larger $(n=2074)$ trial, the ICON3 comparing paclitaxel against two nontaxane arms (either single agent carboplatin or combination CTX, doxorubicin, and cisplatin) was negative. ${ }^{[3]}$ Despite controversies $^{[4]}$ including concerns about a suboptimal control arm, CTX was consigned to the dustbin of 
chemotherapy history; a recent meta-analysis ${ }^{[5]}$ ignored most of these trials.

However, with increasing knowledge of molecular heterogeneity of ovarian cancer, there appears to be a role for CTX. At least, $15 \%$ of high grade serous ovarian cancer occur in women with germline BRCA $1 / 2$ mutation, and another, $35 \%$ may have acquired defects in the HR pathway. ${ }^{[6]}$ These tumors are well known for being sensitive to poly (ADP-ribose) polymerase inhibitors, and also sensitive to DNA damaging agents such as cisplatin and alkylating agents such as CTX. ${ }^{[7]}$ Conversely, cell lines displaying "BRCAness" appear to be resistant to microtubule poisons such as taxanes. ${ }^{[8]}$

While data from cell lines and animal models are encouraging, clinical data supporting a role for CTX in HR deficient ovarian cancer is limited. A case report ${ }^{[9]}$ documents a patient with BRCA2 mutation treated with oral melphalan for a year in 1985 and was apparently cured (No evidence of disease 26 years later). A phase II randomized trial ${ }^{[10]}$ with metronomic oral CTX alone or in combination with veliparib (a PARP inhibitor) in a heterogeneous cohort (31 of 72 evaluable patients were BRCA mutants) showed significant responses to CTX. Of the 7 patients who responded (including one complete response), four were BRCA mutants; the addition of veliparib did not improve responses in this trial. In sharp contrast to the inability of a PARP inhibitor to add to the efficacy of CTX, addition of olaparib to paclitaxel and carboplatin (i.e., an alkylating agent free combination) improved progression free survival in another trial. ${ }^{[1]}$

Alkylating agents are a part of contemporary combination therapy regimens in breast cancer, and HR deficient breast cancers will continue to benefit. However, the replacement of CTX with paclitaxel in ovarian cancer would have deprived a significant percentage of these patients of such benefit.

In summary, sensitivity to alkylating agents in HR deficient (including BRCA mutated) ovarian cancers is a low hanging fruit that should be exploited. It is time to design a trial to reevaluate the role of CTX in HR deficient ovarian cancer.

\section{Financial support and sponsorship}

Nil.

\section{Conflicts of interest}

There are no conflicts of interest.

Ajit Venniyoor

National Oncology Center, Royal Hospital, Muscat, Oman

Address for correspondence:

Dr. Ajit Venniyoor,

Senior Consultant Oncology, National Oncology Center, The Royal Hospital, Post Box 1331, Seeb, Postal Code 111, Muscat,

The Sultanate of Oman.

E-mail: avenniyoor@gmail.com

\section{References}

1. McGuire WP, Hoskins WJ, Brady MF, Kucera PR, Partridge EE, Look KY, et al. Cyclophosphamide and cisplatin compared with paclitaxel and cisplatin in patients with stage III and stage IV ovarian cancer. N Engl J Med 1996;334:1-6.

2. Piccart MJ, Bertelsen K, James K, Cassidy J, Mangioni C, Simonsen E, et al. Randomized intergroup trial of cisplatin-paclitaxel versus cisplatin-cyclophosphamide in women with advanced epithelial ovarian cancer: Three-year results. J Natl Cancer Inst 2000;92:699-708.

3. International Collaborative Ovarian Neoplasm Group. Paclitaxel plus carboplatin versus standard chemotherapy with either single-agent carboplatin or cyclophosphamide, doxorubicin, and cisplatin in women with ovarian cancer: The ICON3 randomised trial. Lancet 2002;360:505-15.

4. Hawkins RE. Chemotherapy for ovarian cancer - Trials, controversies and funding. Br J Cancer 1998;78:1402-3.

5. Yang L, Guo G, Sun L, Li C, Zhang H. Efficacy and safety of traditional chemotherapies for patients with ovarian neoplasm: A network meta-analysis. Oncotarget 2017;8:59867-77. [Doi: 10.18632/oncotarget.16729].

6. Pothuri B. BRCA1- and BRCA2-related mutations: Therapeutic implications in ovarian cancer. Ann Oncol 2013;24 Suppl 8:viii22-7.

7. Fu D, Calvo JA, Samson LD. Balancing repair and tolerance of DNA damage caused by alkylating agents. Nat Rev Cancer 2012;12:104-20.

8. Lafarge S, Sylvain V, Ferrara M, Bignon YJ. Inhibition of BRCA1 leads to increased chemoresistance to microtubule-interfering agents, an effect that involves the JNK pathway. Oncogene 2001;20:6597-606.

9. Osher DJ, Kushner YB, Arseneau J, Foulkes WD. Melphalan as a treatment for BRCA-related ovarian carcinoma: Can you teach an old drug new tricks? J Clin Pathol 2011;64:924-6.

10. Kummar S, Oza AM, Fleming GF, Sullivan DM, Gandara DR, Naughton MJ, et al. Randomized trial of oral cyclophosphamide and veliparib in high-grade serous ovarian, primary peritoneal, or fallopian tube cancers, or BRCA-mutant ovarian cancer. Clin Cancer Res 2015;21:1574-82.

11. Oza A, Cibula D, Benzaquen A, Poole C, Mathijssen R, Sonke $\mathrm{G}$, et al. Olaparib combined with chemotherapy for recurrent platinum-sensitive ovarian cancer: A randomised phase 2 trial. Lancet Oncol 2015;16:87-97.

This is an open access journal, and articles are distributed under the terms of the Creative Commons Attribution-NonCommercial-ShareAlike 4.0 License, which allows others to remix, tweak, and build upon the work non-commercially, as long as appropriate credit is given and the new creations are licensed under the identical terms.

\begin{tabular}{|l|l|}
\hline \multicolumn{2}{|c|}{ Access this article online } \\
\hline Quick Response Code: & Website: \\
\hline & www.ijmpo.org \\
\cline { 2 - 2 } & DOI: \\
\hline
\end{tabular}

How to cite this article: Venniyoor A. Cyclophosphamide in ovarian cancer subtypes: Time for a comeback. Indian J Med Paediatr Oncol 2018;39:551-2.

C 2018 Indian Journal of Medical and Paediatric Oncology | Published by Wolters Kluwer - Medknow 